\title{
Genetic characterisation of a porcine bocavirus detected in domestic pigs in Uganda
}

\author{
Anne-Lie Blomström • Karl Ståhl • \\ Ademun Rose Okurut $\cdot$ Charles Masembe • \\ Mikael Berg
}

Received: 24 September 2012/ Accepted: 21 November 2012/Published online: 9 December 2012

(C) Springer Science+Business Media New York 2012

\begin{abstract}
Porcine bocaviruses (PoBoVs) are small linear ssDNA viruses belonging to the genus bocavirus in the family Parvoviridae. The genome encodes four proteinsthe non-structural protein 1 (NS1), the NP1 protein (unknown function) and the two structural proteins VP1 and VP2. In recent years, a number of different highly divergent PoBoV species have been discovered. PoBoVs have been shown to be present in pig populations in Europe, Asia and in the United States of America. In this study, we present the first data of the presence of PoBoV in Africa, specifically in Uganda. A PCR targeting a PoBoV species that have previously been detected in both Sweden and China was used to screen 95 serum samples from domestic pigs in Uganda. Two pigs were found to be positive for this specific PoBoV and the complete coding region was amplified from one of these samples. The amino acid sequence comparison of all these proteins showed a high identity (98-99\%) to the published Chinese sequences (strains: H18 and SX) belonging to the same PoBoV species. The same was true for the Swedish sequences from the same species. To the other PoBoV species the divergence was higher and only a $28-43 \%$ protein sequence identity was seen comparing the different proteins.
\end{abstract}

A.-L. Blomström $(\bowtie) \cdot$ K. Ståhl · M. Berg

Section of Virology, Department of Biomedical Sciences and

Veterinary Public Health, Swedish University of Agricultural

Sciences, Box 7028, 75007 Uppsala, Sweden

e-mail: anne-lie.blomstrom@slu.se

\section{A. R. Okurut}

Ministry of Agriculture Animal Industry and Fisheries, Entebbe, Uganda

C. Masembe

College of Natural Sciences, Makerere University, Kampala, Uganda
Keywords Genetic analysis · Porcine bocavirus · Uganda

Porcine bocaviruses (PoBoVs) are small non-enveloped linear ssDNA viruses belonging to the genus bocavirus in the family Parvoviridae. Other members in the same genus are bovine parvovirus, canine minute virus and human bocaviruses. All parvovirus genomes consist of a non-structural ORF (NS1) at the $5^{\prime}$-end and an ORF at the $3^{\prime}$-end encoding for the capsid proteins (VP1 and VP2), but bocaviruses are unique having an additional third ORF situated between these two, encoding for a protein (NP1) of unknown function [1, 2]. Since 2009, a number of different PoBoVs have been discovered and characterised around the world. The first PoBoV was discovered in a metagenomic study in Sweden investigating the viral flora of pigs suffering from postweaning multisystemic wasting syndrome. The genome of this virus was only partially sequenced ( 1890 nt) [3, 4]; however, since then the virus has also been detected in China [5] and the complete genome has been sequenced $[5,6]$. In the following years, highly divergent PoBoVs were discovered. For example, in 2010 in China, PoBoV1 and 2 were discovered and the complete genomes were genetically characterised; in the same study the partial genomes of two additional $\mathrm{PoBoV}(6$ and $7 \mathrm{~V})$ were described [7]. Also in Hong Kong two novel bocaviruses, PoBoV3 and 4, were discovered [8]. As the non-structural gene of these PoBoVs has $<95 \%$ sequence identity, according to the existing criteria for bocavirus classification by the International Committee of Taxonomy of Viruses (http://www. ictvdb.org) they can be classified into different species. In addition to these and other PoBoVs additional related novel porcine parvoviruses (PPV) have been discovered and characterised-PPV4 in the United States of America [9] and porcine hokovirus in Hong Kong [10]. 
The pathogenicity of these viruses remains unclear but studies from Europe, Asia and the United States of America indicate that these discovered viruses are widespread in porcine populations worldwide. At present, no data of the presence of these viruses on the African continent are available. Our group has in a previous study investigated 95 serum samples from domestic pigs in Uganda for the presence of Torque Teno Sus virus 1 and 2 (TTSuV-1 and 2) [11].

In the present work, we used DNA extracted in the above-mentioned study. In brief, the majority of the samples were extracted using DNeasy Blood \& Tissue kit (Qiagen) according to the protocol 'Purification of Total DNA from Animal Blood or Cells' provided by the manufacturer. Few of the samples were extracted through combining TRIzol (Invitrogen), back extraction buffer (4 M Guanidine Thiocyanate, $50 \mathrm{mM}$ Sodium Citrate, $1 \mathrm{M}$ Tris) and QIAamp DNA mini kit (Qiagen) [11]. Primers targeting an approx. 700-nt long region covering the end of NP-1 and the beginning of VP1/2 were used for the PCR screening [3, 4]. The PCR of the 95 DNA samples was run using AmpliTaq Gold DNA polymerase (ABI) according to the following protocol: $1 \times$ PCR buffer, $2.5 \mathrm{mM} \mathrm{MgCl}_{2}$, $0.2 \mathrm{mM}$ of each nucleotide, $0.4 \mathrm{mM}$ forward primer $\left(5^{\prime}-\mathrm{G}\right.$ CACTTCAGATTTACTGAATGT-3'), $0.4 \mathrm{mM}$ reverse primer (5'-GTCTTTGCCAGTCATTTGGAGA-3') and 1.25 U AmpliTaq Gold DNA polymerase. Amplification was initiated with a 12 min heating step at $95{ }^{\circ} \mathrm{C}$ followed by 40 cycles of $30 \mathrm{~s}$ at $95{ }^{\circ} \mathrm{C}, 30 \mathrm{~s}$ at $58^{\circ} \mathrm{C}$ and $90 \mathrm{~s}$ at $72{ }^{\circ} \mathrm{C}$. The amplification was ended with a final elongation step at $72{ }^{\circ} \mathrm{C}$ for $10 \mathrm{~min}$ and the PCR products were run on the gel (data not shown). Two samples out of the 95 were positive for the PoBoV-one sample was strongly positive while the other only displayed a weak band on the gel. The weak band contained to small amounts of DNA for sequence analyses and, therefore, was only one out of the two positive samples used in the continued analysis. The PCR product was purified with Qiagen PCR purification kit (QIAGEN) and eluted in $30 \mu \mathrm{EB}$ before being sent for sequencing (Macrogen, Korea). As the sequencing confirmed the presence of $\mathrm{PoBoV}$ the complete coding region was amplified. The primers $138 \mathrm{~b}$ and $93 \mathrm{~b}$ [4] were used to amplify a region covering 1890-nt of the genome. The remaining genome was amplified using primers designed based on the start and the end of the coding region of two PoBoV genomes (accession number: HQ223038 (SX) and HQ291308 (H18)) that have shown high similarity [6, 12] to the targeted PoBoV [4]. The PCR and sequencing was performed as described above. To ensure sequence accuracy each specific base was sequenced at least four times. SeqMan (Lasergene 9.1, DNASTAR) was used to assemble all the sequences and to view and edit the sequences. The assembled genome was 4667 nucleotides in length
(GenBank accession number: JX854557) and using sixpack (EMBOSS) three ORFs were identified corresponding to NS1 (637 amino acids), NP1 (218 amino acids) and VP1/2 (620 amino acids). To compare and analyse the genome in relation to previously described PoBoVs the complete genomes of PoBoVs representing the different species were downloaded from GenBank, and the same was done for the amino acid sequences available for each of the three proteins. ClustalW and sequence identity analysis was performed using Bioedit (http://www.mbio.ncsu.edu/bioedit/ bioedit.html) and a neighbour-joining tree with a bootstrap value of 1000 was constructed using Mega5 [13] to display the phylogenetic relationship. The complete genome displayed the closest sequence identity to the abovementioned PoBoV strains from China-SX (99\%) and H18 $(90 \%)$. As the complete genome from the Swedish PoBoV is not yet available, it was not included in the analysis, but the 1890-nt region available showed a $99 \%$ nucleotide sequence identity to the corresponding region in the Ugandan PoBoV. Around $45 \%$ sequence identity was seen to the other PoBoV species over the complete genome (data not shown). Similar results were seen comparing the amino acid sequence of each protein (Table 1). Across all proteins, the identity to the PoBoV-SX [6] was the highest with a sequence identity of 98-99 \%. The PoBoV-H18 [12] also displayed a high sequence identity (99-100\%) for the NP1 and VP1/2 proteins. However, the NS1 only displayed $80 \%$ identity. For the PoBoVs belonging to other species the sequence identity varied between 28 and $43 \%$. The sequence divergence across the entire genes was not equally distributed. In general, the sequence identity between the NS1 sequences as well as between NP1 sequences was higher at the second half of each respective gene. The VP1/2 had an $\sim 400$ nucleotide long region in the first half of the gene as well as a region at the very end of the gene with higher sequence identity compared to other parts of the gene. Functional and structural studies have to be performed to conclude why these specific regions are more conserved. In the phylogenetic analysis (Fig. 1), the PoBoV from this study formed a separate clade together with PoBoV strains: H18, SX and the Swedish bocavirus (swebo). The other different PoBoV species also grouped with each respective member. For verification of the phylogenetic relationship displayed using the Neighbour-joining method, approaches like maximum parsimony and maximum likelihood were also used on the same datasets i.e. on the complete genome, the NS1 protein and on the VP1/2 protein, and all showed similar results (data not shown).

In conclusion, in this study we show for the first time the presence of PoBoV in domestic pigs on the African continent, specifically in Uganda. In the sample set, consisting of 95 serum samples from six different districts [11], only 
Table 1 Protein sequence identity in percentage

The complete amino acid sequence for each protein is compared between the Ugandan sequence (JX854557) and to those of representatives from different species

\begin{tabular}{llllllll}
\hline & $\begin{array}{l}\text { PoBoV } \\
\text { (strain H18) } \\
\text { HQ291308 }\end{array}$ & $\begin{array}{l}\text { PoBoV } \\
\text { (strain SX) } \\
\text { HQ223038 }\end{array}$ & $\begin{array}{l}\text { PoBoV1 } \\
\text { HM053693 }\end{array}$ & $\begin{array}{l}\text { PoBoV2 } \\
\text { HM053694 }\end{array}$ & PoBoV3 & JoBoV4 & PoBoV5 \\
\multicolumn{2}{l}{ JX854557 } & & & & & & \\
NS1 & 80 & 99 & 41 & 42 & 37 & 37 & 37 \\
NP1 & 99 & 99 & 37 & 40 & 28 & 28 & 29 \\
VP1/2 & 100 & 98 & 43 & 42 & 32 & 32 & 32 \\
\hline
\end{tabular}

Fig. 1 Phylogenetic relationship between bocaviruses. The evolutionary history was inferred using the Neighbour-joining method, with a bootstrap test of 1000 replicates. The evolutionary distances were computed using the p-distance method. The complete amino acid sequence for the NP1 protein was used and the viral sequence characterised in the present study is marked with diamond. $B P V$ bovine parvovirus, $C M V$ canine minute virus, $\mathrm{HBoV}$ human bocaviruses, $C B V$ canine bocavirus, $F B o V$ feline bocavirus, $G B o V$ gorilla bocavirus

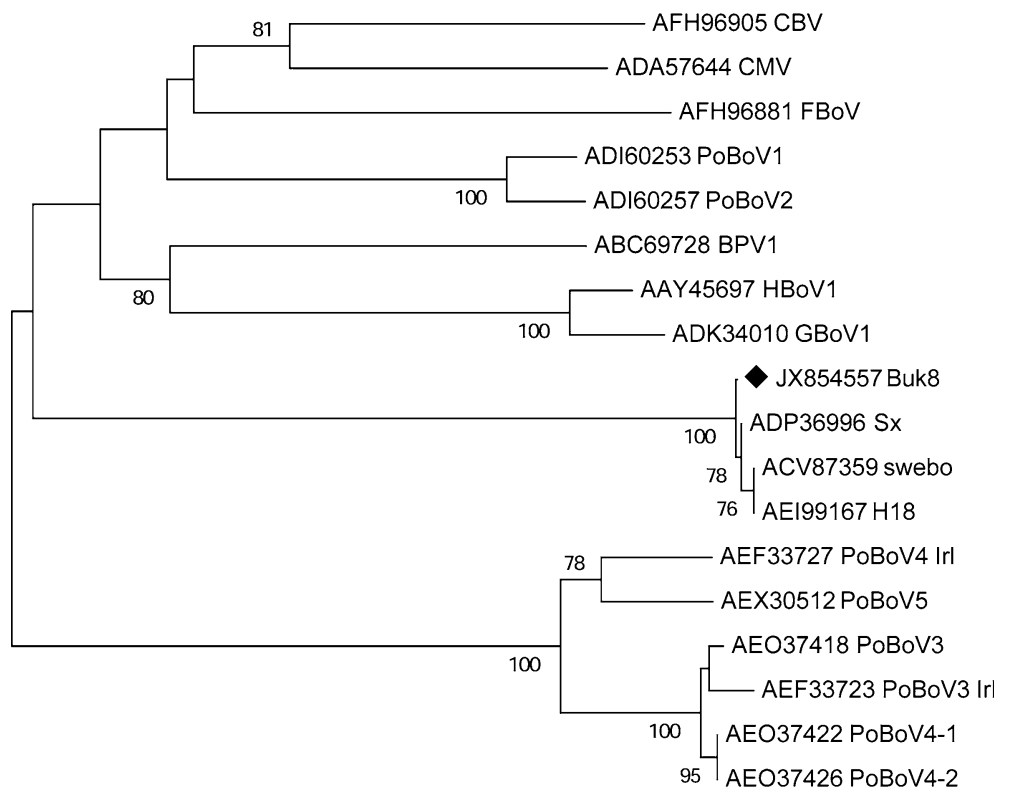

two were positive for the PoBoV. This was a considerably lower detection rate compared to that for TTSuV1 (16.8\%) and for TTSuV2 (48.4\%) using the same sample set. The two PoBoV positive samples were not positive for either TTSuV1 or TTSuV2 in the above-mentioned study. The genetic characterisation of the complete coding region displayed $80-100 \%$ sequence identity to the two most similar published PoBoVs when analysing the different protein sequences. In this study, only one of the currently known PoBoVs species was detected; however, it is considered highly likely that a more extensive investigation would show that additional PoBoV species are also present in Uganda as has been demonstrated in other parts of the world.

Acknowledgments We would like to thank the District Veterinary Officers and field support staff in the included districts for assistance during sampling, and our colleagues Denis Muhangi and Susan Ndyanabo for technical assistance in the lab and in the field. Financial support for this study was obtained from the Swedish International Development and Cooperation Agency (Sida; SWE-2009-081), the research Council Formas (221-2009-1984) and the Swedish Ministry of Foreign Affairs as part of its special allocation on global food security (through the Swedish University of Agricultural Sciences, SLU).

\section{References}

1. K. Hueffer, C.R. Parrish, Curr. Opin. Microbiol. 6, 392-398 (2003)

2. X.J. Meng, Transbound Emerg. Dis. (2012)

3. A.L. Blomström, S. Belak, C. Fossum, L. Fuxler, P. Wallgren, M. Berg, Virus Res. 152, 59-64 (2010)

4. A.L. Blomström, S. Belak, C. Fossum, J. McKillen, G. Allan, P. Wallgren, M. Berg, Virus Res. 146, 125-129 (2009)

5. S. Zhai, C. Yue, Z. Wei, J. Long, D. Ran, T. Lin, Y. Deng, L. Huang, L. Sun, H. Zheng, F. Gao, S. Chen, S. Yuan, Arch. Virol. 155, 1313-1317 (2010)

6. S. Zeng, D. Wang, L. Fang, J. Ma, T. Song, R. Zhang, H. Chen, S. Xiao, J. Gen. Virol. 92, 784-788 (2011)

7. W.X. Cheng, J.S. Li, C.P. Huang, D.P. Yao, N. Liu, S.X. Cui, Y. Jin, Z.J. Duan, PLoS ONE 5, e13583 (2010)

8. S.K. Lau, P.C. Woo, C.C. Yip, K.S. Li, C.T. Fu, Y. Huang, K.H. Chan, K.Y. Yuen, J. Gen. Virol. 92, 2047-2059 (2011)

9. A.K. Cheung, G. Wu, D. Wang, D.O. Bayles, K.M. Lager, A.L. Vincent, Arch. Virol. 155, 801-806 (2010)

10. S.K. Lau, P.C. Woo, H. Tse, C.T. Fu, W.K. Au, X.C. Chen, H.W. Tsoi, T.H. Tsang, J.S. Chan, D.N. Tsang, K.S. Li, C.W. Tse, T.K. 
Ng, O.T. Tsang, B.J. Zheng, S. Tam, K.H. Chan, B. Zhou, K.Y.

Yuen, J. Gen. Virol. 89, 1840-1848 (2008)

11. M. Brink, K. Stahl, C. Masembe, A.R. Okurut, M. Berg, A.L. Blomstrom, Virol. J. 9, 39 (2012)
12. T. Shan, D. Lan, L. Li, C. Wang, L. Cui, W. Zhang, X. Hua, C. Zhu, W. Zhao, E. Delwart, PLoS ONE 6, e17292 (2011)

13. K. Tamura, J. Dudley, M. Nei, S. Kumar, Mol. Biol. Evol. 24, 1596-1599 (2007) 